\title{
Chronic sarcoid synovitis in the Caucasian: an arthroscopic and histological study
}

\author{
D. G. I. SCOTT, ${ }^{1}$ L. O. R. PORTO, ${ }^{1}$ C. R. LOVELL, ${ }^{2}$ AND \\ G. O. THOMAS ${ }^{3}$
}

From the ${ }^{1}$ Royal National Hospital for Rheumatic Diseases, ${ }^{2}$ Bristol Royal Infirmary, and ${ }^{3}$ Neville Hall Hospital, Abergavenny

SUMmARY Chronic synovitis is a rare complication of sarcoidosis, virtually confined to the black population. Synovial histology may be nonspecific or show typical sarcoid granulomata. We report 2 cases of chronic sarcoid synovitis in Caucasians. Histology showed typical granulomata in one patient, whose distinctive arthroscopic appearance is discussed.

\section{Case reports}

\section{CASE 1}

A 35-year-old Caucasian male developed uveitis of his left eye in 1975 which responded slowly but effectively to local treatment. Hilar lymphadenopathy was noted on a routine chest $x$-ray, and a diagnosis of sarcoidosis was made, confirmed by a negative Mantoux (1/100) and a positive Kveim test. There was no history of erythema nodosum.

In 1976 he developed a persistent synovitis of both knees, ankles, and his right elbow, with recurrent effusions and the development of $15^{\circ}$ fixed flexion deformity of the elbow. Anti-inflammatory drugs and local corticosteroid injections controlled the synovitis until 1978, when again large effusions of his knees developed. Arthroscopy of the right knee showed a proliferative synovitis with numerous small villi. There was no crystal deposition and the cartilage appeared normal.

Synovial biopsy showed thickening of the lining membrane up to 3 cells wide, and increased vascularity of the underlying stroma with some lymphocytic infiltration. Serial sections failed to reveal any sarcoid granulomata. Investigations: Haemoglobin $15 \cdot 1 \mathrm{~g} / \mathrm{dl}$; leucocytes $5 \cdot 1 \times 10^{9} / 1 ;$ ESR $7 \mathrm{~mm} / \mathrm{h}$; urea and electrolytes, liver function tests, calcium, phosphate, alkaline phosphatase, uric acid, and urinary calcium excretion all normal. RA latex and antinuclear antibodies tests negative and im-

Accepted for publication 2 April 1980

Correspondence to Dr D. G. I. Scott, Department of Medicine, Southmead Hospital, Southmead Road, Bristol BS10 $5 \mathrm{NB}$. munoglobulins normal. Chest radiograph showed bilateral hilar lymphadenopathy, with enlargement of the right paratracheal glands and increased linear shadowing of the perihilar region.

A repeat arthroscopy in 1.979 showed no progression, but there was persistence of the proliferative synovitis, and a biopsy showed similar changes to those seen in 1978.

\section{CASE 2}

A 43-year-old Caucasian works foreman of pure Welsh descent presented in April 1977 with a 3month history of painless, bluish-red nodules on the upper back and arms. He gave a history of recurrent soreness and redness of the eyes, but was otherwise well. Examination showed discrete, dusky-red nodules on the arms and trunk, and small conjunctival nodules.

Investigations: Plasma viscosity 1.84 (normal 1.5-1.72); blood count, urine, and serum calcium normal; Heaf test negative, Kveim test positive. $X$-rays of his hands showed symmetrical erosions in the margins of the hamates and bases of the 5th metacarpals. Skin biopsy of a nodule showed numerous epithelioid granulomata with Langhans type giant cells.

During the succeeding 6 months he became generally unwell with recurrent sore eyes, and was started on prednisolone $5 \mathrm{mg} 4$ times daily with marked improvement. The dose was gradually reduced, and was discontinued in August 1978. In September he noticed numerous new lesions on the arms, and trunk, and a large fluctuant swelling behind both knees. An arthrogram of the right knee 
confirmed a large popliteal cyst. The RA latext test was negative. Both the skin lesions and the popliteal cysts showed clinical regression after restarting prednisolone $5 \mathrm{mg} 4$ times daily. Since then attempts at stopping the prednisolone have resulted in recurrence of the knee swelling and cutaneous lesions, and he was referred to Bath for arthroscopy in July 1979.

At arthroscopy the right knee showed hypertrophic changes in the synovial tissue with large numbers of very thin, grass-like villi (Fig. 1). There was no crystal deposition. Synovial biopsy showed numerous sarcoid granulomata and villous proliferation with very little acute inflammation (Fig. 2).

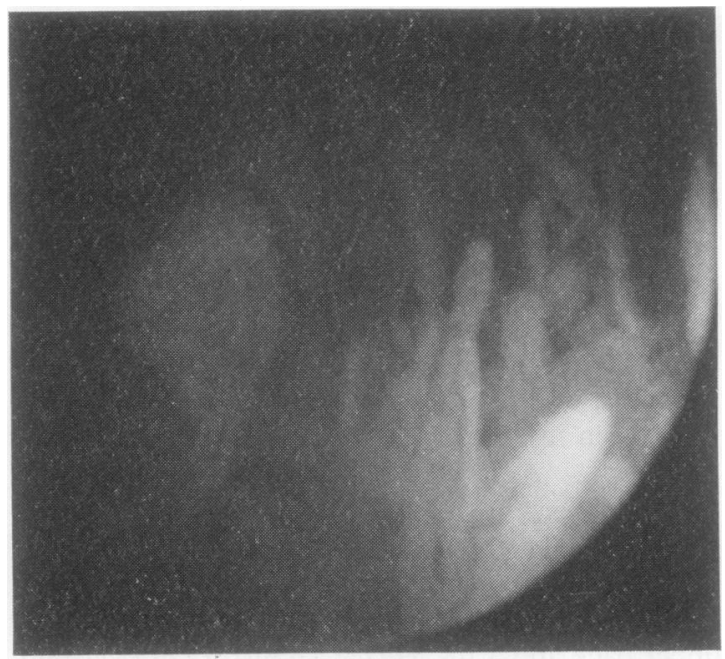

Fig. 1 Arthroscopy showing thin grass-like villi.

\section{Discussion}

Sarcoidosis has a reported incidence of $0.02-0.2 \%$ of the population and is commoner in blacks (10 blacks : 1 white). ${ }^{1}$ A transient acute oligoarthritis (which is often a 'periarthritis') is common in patients with erythema nodosum with a reported incidence of up to $40 \% \%^{1-5}$ Chronic skeletal involvement in sarcoid includes bone, ${ }^{167}$ tendon sheath, ${ }^{8}$ and dactylitis, ${ }^{7}$ but chronic synovitis ${ }^{\mathbf{1 5}}$ is rare, with an incidence of less than $0 \cdot 2 \%$, and is virtually confined to the black population. ${ }^{2}{ }^{8} 9$ Synovial histology in chronic arthritis may be nonspecific with mild chronic inflammatory changes with or without villous proliferation, but typical granulomata were found in about half the cases reported. 581011

Such granulomata have been described in Caucasians but only in 2 individual case reports from the 1950 s. Turek ${ }^{12}$ reported, as a rarity, a 52-yearold white man with persistent pain and swelling in the left ankle. Open biopsy showed typical granulomata involving the border of adjacent cartilage but the joint capsule was not involved. Morse ${ }^{13}$ described a 34-year-old white man with chronic arthritis of the left wrist. Open biopsy revealed typical sarcoid granuloma in the synovium. Despite a positive tuberculin skin test the arthritis did not respond to conventional antituberculosis treatment.

Arthroscopy is a safe and simple procedure which has been shown to be most useful in the assessment and diagnosis of patients with large joint arthritis. ${ }^{14}$ Arthroscopic findings have been reported once before in chronic sarcoid synovitis in $1936 .^{10} \mathrm{Grape}-$ like clusters of reddish tissue were thought to represent sarcoid tissue, but a punch biopsy revealed

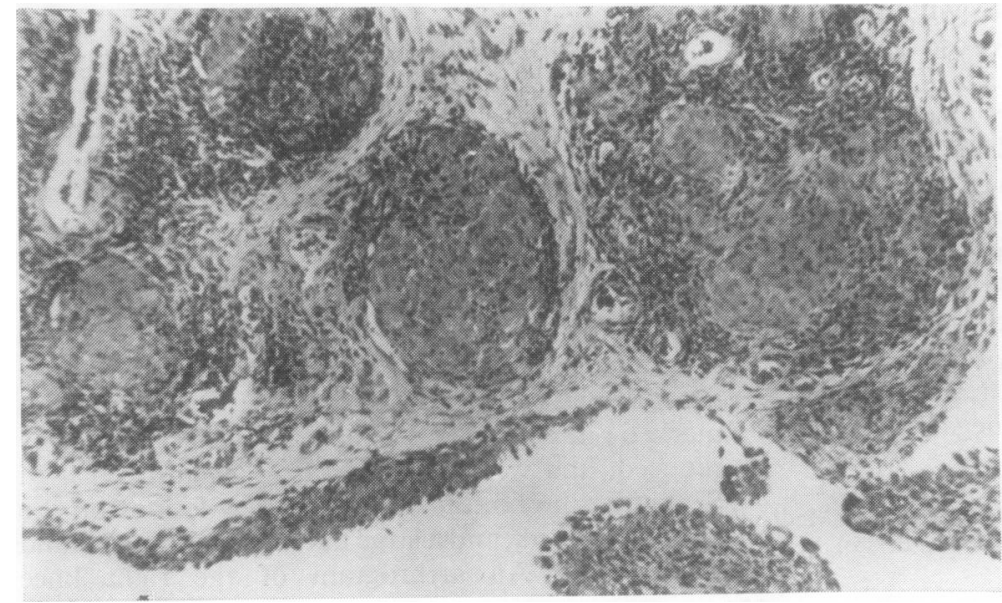

Fig. 2 Synovial biopsy showing typical sarcoid granulomata. 
nonspecific synovitis only. An open biopsy from the peroneal sheath showed similar tissue, and sarcoid tubercules were seen on microscopic examination. Although the appearances we have described differ from those reported by Burman and Mayer, ${ }^{10}$ the value of arthroscopy and biopsy is still shown by our patients. One patient (case 1) had a nonspecific arthroscopic and histological appearance. The other patient (case 2), however, had an unusual arthroscopic appearance of thin, gross-like villi unlike any previously recorded at arthroscopy ${ }^{14}$ and typical sarcoid granulomata on biopsy.

Further arthroscopic examinations are necessary before this unusual appearance can be considered typical of chronic sarcoid synovitis. The 2 types of chronic sarcoid arthritis, both the nonspecific and the true sarcoid granulomatous synovitis, are illustrated here and must now be accepted as a complication of this disease in the Caucasian population.

We thank Dr P. A. Bacon for his encouragement and for permission to report the cases, and Miss Anne Brown for typing the manuscript.

\section{References}

1 James D G, Nevill E, Carstairs L S. Bone and joint sarcoidosis. Semin Arthritis Rheum 1976; 1: 53-81.
2 Bianchi F. A., Keech M K. Sarcoidosis with arthritis. Ann Rheum Dis 1964; 23: 463-79.

3 Gumpel J M, Johns C S, Shulman L E. The joint disease of sarcoidosis. Ann Rheum Dis 1967; 26: 194-205.

4 Gendel B R, Young J M, Greiner D J. Sarcoidosis: review with 24 additional cases. Am J Med 1952; 7: 205-18.

5 Kaplan H. Sarcoid arthritis. Arch Intern Med 1963; 112: 924-35.

6 Schriber R A, Firrozna H. Extensive phalangeal cystic lesions: Sarcoidosis limited to the hands and feet? Arthritis Rheum 1975; 18: 123-8.

7 Spilberg I, Siltzbach L, McEwan C. The arthritis of sarcoidosis. Arthritis Rheum 1969; 12: 126-37.

8 Sokoloff L, Bunim, J J. Clinical and pathological studies of joint involvement in sarcoidosis. N Engl J Med 1959; 260: 841-7.

9 Bjarnason D F, Forrester D M, Swezy R L. Destructive arthritis of the large joints. $J$ Bone Joint Surg 1973; 55A: 618-22.

10 Burman M S, Mayer L. Arthroscopic examination of the knee joint: report of cases observed in the course of arthroscopic examination, including instances of sarcoid and multiple polypoid fibromatosis. Arch Surg 1936; 32: 846-74.

11 Rodnan G P, Unis E J, Totten R S. Experience with punch biopsy of synovium in this study of joint disease. Ann Intern Med 1960; 53: 319-31.

12 Turek S L. Sarcoid disease of bone at the ankle joint. J Bone Joint Surg 1953; 35A: 465-8.

13 Morse J O. Sarcoidosis with joint involvement. J Okla State Med Assoc 1959; 52: 676-80.

14 Jayson M I V. Arthroscopy. Clin Rheum Dis 1976; 2: 77-91. 